\title{
15. Conservation consequences of unstable taxonomies: The case of the red colobus monkeys
}

\author{
John Oates and Nelson Ting
}

\section{Introduction}

Species are the common primary 'currency' used in biodiversity conservation planning. Regions and ecosystems are often prioritised for conservation action based on measures of species richness and endemism (e.g. Myers et al., 2000; Olson and Dinerstein, 2002), and species judged to be in danger of extinction are usually given special attention (e.g. with focused conservation action plans produced by the International Union for Conservation of Nature's Species Survival Commission (IUCN SSC); see www.iucn.org/about/work/programmes/ species/publications/species_actions_plans/). Such species-based thinking is quite understandable. From long before there was any science of biology or taxonomy, people around the world have recognised sets of similar organisms as distinct entities (and given names to these sets); this 'natural' species concept provided the basis for the work of Linnaeus and those who have followed him. With or without scientific classification, people would recognise horses as different from asses and lions as different from tigers, and factor this recognition into their world view and decision making. When science is brought fully into play in conservation planning, however, a species-based approach can lead to serious difficulties in determining conservation priorities in those cases where a group of organisms has a poorly resolved or unstable species-level classification. Difficulties arise both in establishing relative conservation priorities within that group, and in relation to other groups. Unstable classification also creates problems for communicating information to policy-makers and managers who may have little knowledge of taxonomy.

Among primates, the taxonomy of Africa's red colobus monkeys has been particularly unstable and contentious. A great number of different classifications have been published in the last 45 years, recognising between one and 16 species. Several of these different classifications have been produced by Colin Groves, who has long been interested in this group of monkeys (e.g. Groves, 1989, 2001, 2007). Groves' classificatory changes have been influenced not only by new research findings, but also by his move from using the Biological Species Concept (BSC) as the basis of taxonomic analysis to the Phylogenetic 
Species Concept (PSC). The frequent, and often quite radical, changes in red colobus classifications have led to confusion both among field workers studying behaviour and undertaking surveys, and in conservation assessments published by national and international organisations. This has been particularly problematic because red colobus monkeys are among the most endangered primates in Africa with numerous populations in danger of extinction due to hunting or habitat modification by humans (Oates, 1996). With no consensus on their classification and on which forms are particularly distinct, it has been difficult to designate conservation priorities for this group of primates.

In this chapter we consider some of the causes and consequences of this example of taxonomic instability. For instance, could particular colobus populations, such as the Critically Endangered Tana River red colobus of Kenya and the probably recently extinct Miss Waldron's red colobus of West Africa, have suffered from a lack of sufficient conservation attention in part through their ambiguous distinctiveness? And could the use of different classifications have influenced the relative priority given to different regions of Africa for primate conservation? Finally, using the red colobus example, we consider what taxonomic practices might most beneficially be applied to conservation without a loss of scientific integrity.

\section{Systematics theory and background}

While no evolutionary biologist would debate the importance of the species concept in the development of evolutionary theory, there has been a lack of consensus on how a species should be defined (Frankham et al., 2012). This is one of the reasons why red colobus monkeys have been so difficult to classify. In fact, the taxonomic issues within this group are related to a larger theoretical debate that dominated the field of systematics in the latter half of the twentieth century. A comprehensive review of the history of this debate is beyond the scope of this chapter, but it is worthwhile highlighting some aspects of the debate particularly relevant to the problem we are discussing here.

A major theoretical divide has arisen between the two approaches that have come to be known as Evolutionary Systematics and Phylogenetic Systematics. The former is rooted in the union of evolutionary theory and population genetics that occurred in the 1940s, now known as 'The Modern Synthesis' (Huxley, 1942), while the latter finds its origins in the cladistic approach advocated by Willi Hennig in his book Phylogenetic Systematics, which was translated into English in 1966. One of the major differences between these two taxonomic schools has been in how they have viewed species. Those following Evolutionary Systematics have typically used process-based species concepts (i.e. considering the process leading to population divergence), while those who have supported Phylogenetic Systematics have generally employed pattern- 
based species concepts (i.e. the patterns resulting from divergence). The bestknown process-based species concept is the biological species concept (BSC), and the most commonly cited pattern-based concept is the phylogenetic species concept (PSC).

Usually credited to Mayr (1942), the BSC only applies to sexually reproducing organisms and defines species as 'groups of interbreeding natural populations that are reproductively isolated from other such groups' (Mayr, 1996: 264). Some authors (e.g. Bock, 2004; Coyne and Orr, 2004) have elaborated on this definition to allow for limited gene flow between two species as long as their respective gene pools are protected from one another. Several other species concepts have been formulated as modifications to the BSC, but it has been argued that many of these are redundant (e.g. Evolutionary Species, Mate Recognition Species; Szalay, 1993; Mayr, 1996). In regard to the PSC, Cracraft's (1983) definition is the most commonly accepted: 'the smallest diagnosable cluster of individual organisms within which there is a parental pattern of ancestry and descent'. This has been further refined to a group of populations with shared and fixed character combinations that represent minimal units appropriate for cladistic analysis (Davis and Nixon, 1992; Groves, 2004). In this sense, it is not so much a 'species concept' but a criterion for the diagnosis of species (Mayr, 1996; Goldstein and DeSalle, 2000). In fact, Groves (2012) states that a more appropriate name for the PSC might have been the 'Diagnosability Species Concept'.

Evolutionary Systematics (and thus the BSC and its derivatives) dominated the field of systematics for decades following the Modern Synthesis. However, the BSC has been criticised on several grounds (see Sokal and Crovello, 1970). One of its biggest shortcomings is the difficulty it creates for species diagnosis when populations do not overlap in distribution, precluding complete confidence in whether or not they would interbreed if brought into contact. In such circumstances, species status is typically given to a population when its differences (usually morphological) from other populations exceed the amount of variation seen within a typical species of the larger taxonomic group to which it belongs. Species diagnosis can thus change depending on what traits are compared and what is regarded as 'typical variation' within a species. This subjectivity has led to a great deal of confusion in the classification of many taxa, including the red colobus monkeys, as we outline below. Frustration over this subjectivity, in combination with the rise of molecular phylogenetics, has led to an increasing acceptance of Phylogenetic Systematics and the PSC over the past couple of decades. No one exemplifies this paradigm shift better than Colin Groves himself; his early classifications of red colobus monkeys (and other taxa) were consistent with the BSC, but more recently he has fully adopted the PSC in his classifications and has advocated for its use (Groves, 2001, 2004, 2012). Table 15.1 displays how red colobus classifications have changed over the years, including Groves' classifications. 
Taxonomic Tapestries

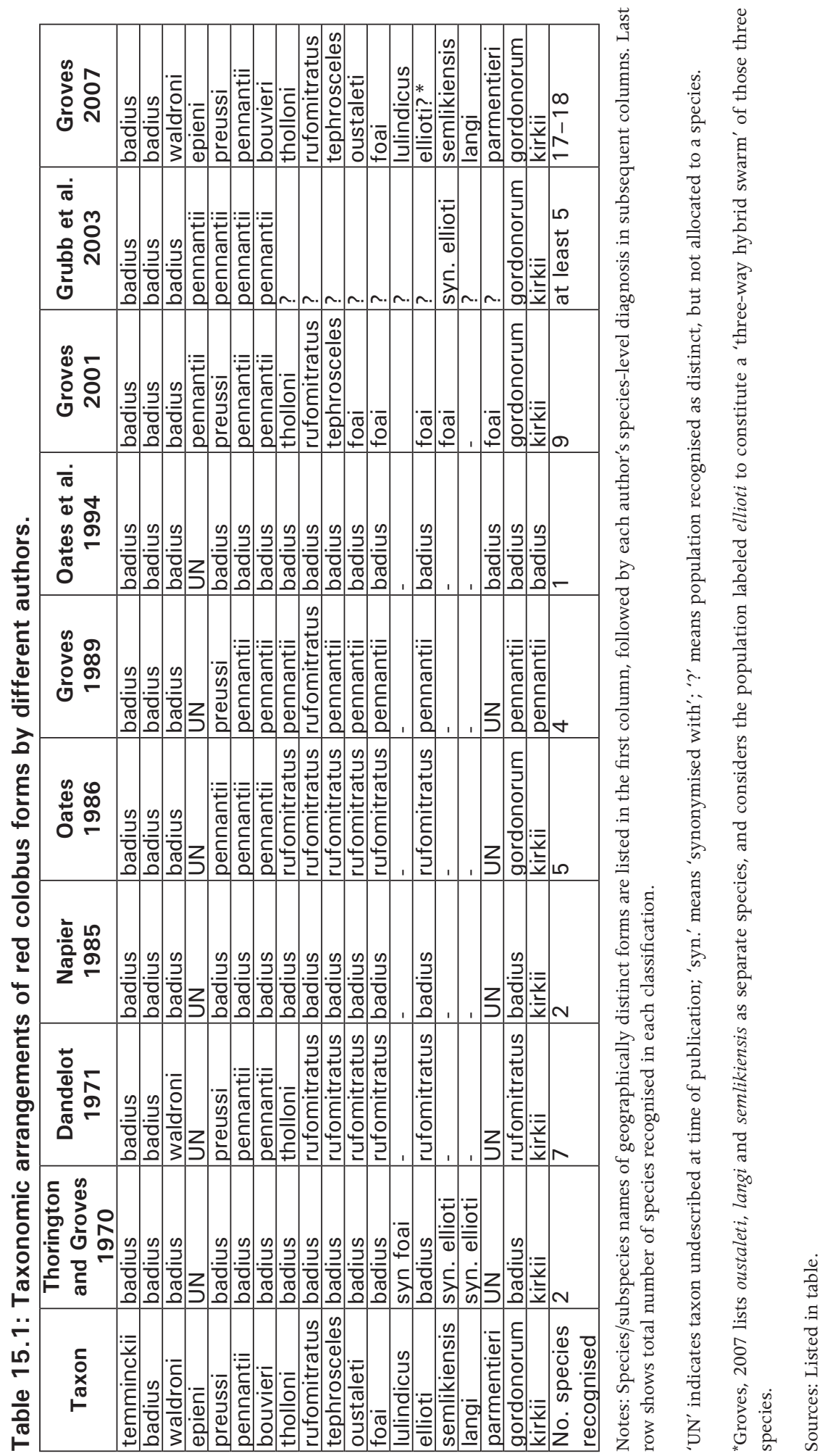




\section{Red colobus monkey distribution and variation}

Red colobus monkeys are commonly regarded as belonging to the subfamily Colobinae of the family Cercopithecidae (Old World monkeys) and they are closely related to the other two living African colobine groups - the olive colobus and the black-and-white colobus. Based largely on pelage differences, 16-18 different forms of red colobus are recognised in many recent classifications (see, e.g. Grubb et al., 2013), distributed across equatorial Africa in a primarily allopatric manner, with the exception being a putative hybrid zone in the eastern Democratic Republic of Congo (Figure 15.1). All populations of red colobus have varying amounts of red, black, white, brown and grey in their pelage, with certain forms showing considerable intra-populational variation, while others are relatively uniform (Kingdon, 1997; Struhsaker, 2010). Red colobus also have a complex and graded vocal system that makes it difficult to classify their vocalisations into discrete categories, unlike the calling array of the blackand-white colobus group (Marler, 1970). Furthermore, their crania display a clinal pattern of size and shape variation across Africa (Cardini and Elton, 2009). These features of red colobus biology have made their classification one of the thorniest issues in African primate taxonomy (Grubb et al., 2003).

Nearly all recently published classifications recognise the same 16-18 different forms of red colobus, with each form regarded as either a subspecies or species; there is thus broad agreement and stability in terms of the recognition of different geographic populations as being taxonomically distinct. The only major exceptions involve populations that occupy the putative hybrid zone in Central Africa. There has been little agreement, however, regarding how many species are present among these 16-18 taxa, and into which species each different form should be classified (see Table 15.1). This is because most classifications of these monkeys have attempted to diagnose species under the BSC, and because the distinct populations are distributed allopatrically objective diagnosis of biological species is extremely difficult, if not impossible. Furthermore, most of the systematic work done has involved comparisons of pelage patterns, which is problematic, given that red colobus coat colour varies at populational and even social group levels. Other research, involving vocalisations or craniometrics, has suffered from incomplete sampling and been confounded by the complex patterns of variation in these monkeys. This has often led to 'giving up' (in the words of Groves, 2001) and a decision to combine all of the red colobus into one species, except sometimes for a few particularly distinct forms. Despite this, most authors have recognised that the level of variation among the different forms does exceed that which is typical for a single primate species under the BSC. 


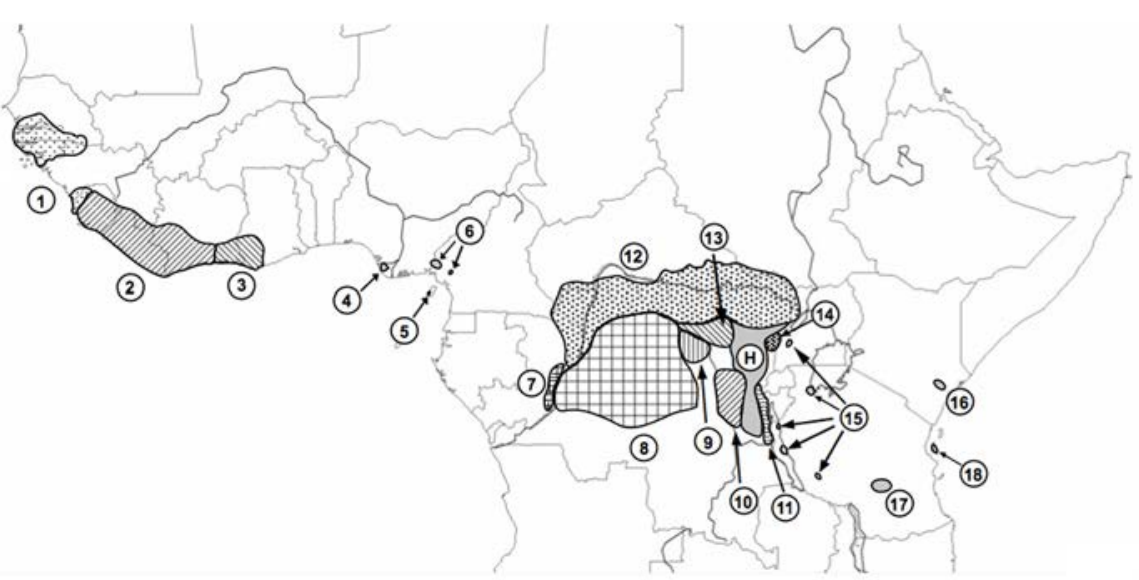

Figure 15.1: Distribution of 18 allopatric populations of red colobus monkeys that have been given taxonomic names of subspecies or species rank. 1, temminckii; 2, badius; 3, waldroni; 4, epieni; 5, pennantii; 6, preussi; 7, bouvieri; 8, tholloni; 9, parmientieri; 10, Iulindicus; 11, foai; 12, oustaleti; 13, langi; 14, semlikiensis; 15, tephrosceles; 16 , rufomitratus; 17, gordonorum; 18 , kirkii. ' $\mathrm{H}$ ' is a putative hybrid population in the eastern Democratic Republic of Congo.

\section{A history of red colobus monkey classification}

Before describing the contentious species-level history of red colobus monkey classification, it is worth noting that the genus-level classification of this group too has changed substantially over the years. Such changes have also in part been caused by paradigm shifts in systematics and likewise may have influenced conservation policy by introducing further confusion. Briefly, most classifications prior to 1980 placed the red colobus monkeys with other African colobines in the genus Colobus. Since then, they have been recognised as (1) the subgenus Piliocolobus within the genus Procolobus, reflecting a close relationship to the olive colobus, or (2) members of a distinct genus, Piliocolobus. These different arrangements result from differences of opinion about what criteria (e.g. morphological variation, genetic variation, time) should be used to diagnose taxa above the species level; there is no current consensus as to which is most appropriate (Goodman, 1996; Groves, 2001).

An important benchmark in the classification of primates in modern times was the publication in 1967 of A Handbook of Living Primates by John and Prudence 
Napier. Napier and Napier followed Verheyen (1962) in recognising just two species of red colobus monkeys, Colobus badius and C. kirkii, which they grouped together in the subgenus Piliocolobus. In the same year, Kuhn (1967) also followed Verheyen in separating $C$. kirkii of Zanzibar from $C$. badius as a monotypic species, and also placed the red colobus in the subgenus Piliocolobus.

Colin Groves, in addition to his doctoral research on gorilla systematics and ecology (Groves, 1966, 1967, 1970a), took an early interest in the systematics of gibbons and leaf-eating monkeys, and co-authored an influential classification of Old World monkeys with Richard Thorington (see also Groves, 1970b). For red colobus, Thorington and Groves (1970) used the classification of Kuhn (1967), but noted that the recognition of several species might be "more in line with taxonomic practice'. In the same volume as Thorington and Groves, Rahm (1970) recognised only one species, Colobus badius, with 14 subspecies, including $C$. b. kirkii, and said that 'no definite answer can be given from the point of view of species and subspecies'. Not long after this, Dandelot (1971) produced a fivespecies classification of red colobus (Colobus badius, C. pennantii, C. rufomitratus, C. tholloni and $C$. kirkii), noting that more extensive research would undoubtedly lead to an increase in the number of species recognised, and suggesting $C$. ellioti, C. preussi and C. waldroni as 'potential' species. Struhsaker (1975) analysed the call repertoires of five different populations generally regarded as subspecies and found $C . b$. preussi to have the most divergent repertoire.

Confusion continued into the 1980s. Extending his earlier analysis of vocalisations to include additional red colobus populations, Struhsaker (1981) identified four clusters of subspecies based on degree of vocal similarity: (1) badius and temminckii; (2) preussi; (3) tholloni, tephrosceles and rufomitratus; and (4) gordonorum and kirkii. Wolfheim (1983) recognised only a single species of red colobus, while P. Napier (1985) retained the two-species arrangement ( $C$. badius and $C$. kirkii) of Kuhn and of Thorington and Groves, citing Verheyen's observation (1962) that kirkii had a relatively small cranial capacity. In an IUCN SSC conservation action plan Oates (1986) - taking account of Struhsaker (1981) - regarded the red colobus monkeys as members of a single superspecies, Procolobus badius, provisionally containing five species: P. badius, P. pennantii, P. rufomitratus, $P$. kirkii and $P$. gordonorum; all the forms found in the central and eastern Congo Basin, together with tephrosceles and rufomitratus of eastern Africa, were grouped together in P. rufomitratus. Groves (1989), however, citing unpublished research by himself and Pierre Dandelot, moved to a fourspecies arrangement, recognising a central species (Colobus pennantii, but which also now included $C$. kirkii), a species restricted to Kenya's Tana River ( $C$. rufomitratus), an Upper Guinea species (C. badius), and $C$. preussi of Cameroon and Nigeria (said to be 'very distinct'). 
In a review of colobine monkey diversity in the mid-1990s, Oates and others (1994) decided to treat all the red colobus as a single species, Procolobus (Piliocolobus) badius, based on the lack of consensus in other classifications. This publication did not contain any new analysis, and did not influence later taxonomic studies, but it did influence conservation listings, as we describe below. Kingdon (1997), by contrast, in a widely used field guide, placed the red colobus in their own genus, Piliocolobus, and used an eight-species classification: P. kirkii, P. gordonorum, P. rufomitratus, P. tholloni, P. oustaleti, P. pennanti [sic], $P$. preussi and $P$. badius.

Since the year 2000, several substantially different taxonomic arrangements of red colobus monkeys have been published, adding to the confusion. The IUCN SSC Primate Specialist Group convened a meeting of primate biologists in Orlando, Florida, in 2000 in an attempt to produce a taxonomic consensus that could be used in conservation planning. This meeting, in which Colin Groves participated, failed to reach a clear consensus on the species-level classification of red colobus. A classification of African primates resulting from the meeting placed the red colobus in the genus Procolobus (subgenus Piliocolobus); it recognised five distinct species ( $P$. badius, $P$. kirkii, $P$. gordonorum, $P$. rufomitratus and $P$. pennantii), and left an additional 5-8 subspecies in a poorly defined 'central assemblage' on which the working group recommended further research to establish relationships (Grubb et al., 2003). This central assemblage of populations is the same group of taxa referred to as $P$. rufomitratus by Oates (1986), except that Grubb and others excluded rufomitratus itself, treating this Tana River red colobus as a separate species. Meanwhile, Groves (2001) had published his influential book Primate Taxonomy, which listed nine species of red colobus, allocated to the genus Piliocolobus: P. badius, P. pennantii, P. preussi, P. tholloni, P. foai, P. tephrosceles, P. gordonorum, P. kirkii and P. rufomitratus.

Later, Groves revised his nine-species classification to a 16-species arrangement by additionally recognising Piliocolobus waldronae, P. epieni, P. bouvieri, $P$. parmientieri, P. oustaleti, P. langi and P. semlikiensis as full species (Groves, 2007). Shortly after this, Ting (2008) presented the results of the first thorough comparison of mitochondrial DNA in red colobus monkeys and proposed instead a five-species arrangement within the genus Procolobus (subgenus Piliocolobus): $P$. badius, $P$. pennantii, $P$. kirkii, P. rufomitratus and $P$. epieni.

Struhsaker (2010), paying special attention to patterns of vocal similarity and difference, recognised seven groups of 'taxa' (badius and relatives, preussi, pennantii, bouvieri, rufomitratus and relatives, gordonorum and kirkii), but was not prepared to allocate these groups, or the populations within them, to named species. In an appendix to Struhsaker's book, Grubb and others (2010) listed 18 subspecies as belonging to a single species, Procolobus badius. 
In the recently published Mammals of Africa, Grubb and others (2013) 'very provisionally' recognise six species: Procolobus badius, $P$. preussi, $P$. pennantii, $P$. rufomitratus, $P$. gordonorum and $P$. kirkii. This is the same arrangement used by Struhsaker (2010), except that these taxa are given species rank, and bouvieri of the Congo Republic is included within P. pennantii.

\section{Effects on conservation planning}

One of the earliest attempts to provide an inventory of threatened species to guide conservation planning was the publication of the Red Data Books by IUCN's Survival Service Commission (known since 1980 as the Species Survival Commission). These publications began to appear in 1966 as loose-leaf datasheet volumes giving information on rare and endangered animals which had come to the attention of IUCN. The first Red Data Book on mammals (Simon, 1966) included 25 species and 22 subspecies of primates judged to be rare or endangered; among these were three red colobus monkeys, listed as Colobus badius kirkii, $C$. b. rufomitratus and C. b. gordonorum. In 1978 Colobus badius preussi was added to the list (Goodwin et al., 1978). In 1980, datasheet publications were superseded by bound volumes, with different volumes covering different groups of taxa, and in 1986 the Red Data Books became the Red List. Table 15.2 compares a selection of IUCN's threat ratings of red colobus taxa from 1978 to 2012.

Table 15.2: Selected threat status listings of red colobus taxa by IUCN.

\begin{tabular}{|l|l|l|l|l|}
\hline Taxon & Red Data Book 1978 & Lee et al.1988 & Red List1996 & Red List2012 \\
\hline temminckii & - & R & EN & EN \\
\hline badius & - & VU & - & EN \\
\hline waldroni & - & EN & CR & CR \\
\hline epieni & UN & UN & EN & CR \\
\hline preussi & EN & EN & EN & CR \\
\hline pennanttii & - & EN & EN & EN \\
\hline bouvieri & - & EN & EN & CR \\
\hline tholloni & - & $\mathrm{K}$ & - & NT \\
\hline rufomitratus & EN & EN & EN & EN \\
\hline tephrosceles & - & VU & - & EN \\
\hline oustaleti & - & $\mathrm{K}$ & - & LC \\
\hline foai & - & $\mathrm{K}$ & $\mathrm{DD}$ & - \\
\hline lulindicus & - & - & $\mathrm{DD}$ & - \\
\hline ellioti & - & $\mathrm{K}$ & - & - \\
\hline semlikiensis & - & - & $\mathrm{DD}$ & - \\
\hline langi & - & - & $\mathrm{DD}$ & - \\
\hline parmentieri & $\mathrm{UN}$ & - & $\mathrm{DD}$ & - \\
\hline gordonorum & $\mathrm{R}$ & $\mathrm{EN}$ & EN & EN \\
\hline kirkii & $\mathrm{R}$ & $\mathrm{EN}$ & EN & EN \\
\hline
\end{tabular}

Notes: $\mathrm{CR}=$ Critically Endangered; DD = Data Deficient; EN = Endangered; $\mathrm{K}=$ Insufficiently Known; LC = Least Concern; NT = Not Threatened; $\mathrm{R}=$ Rare; $\mathrm{UN}=$ Undescribed; $\mathrm{VU}=$ Vulnerable; a dash indicates that the taxon was not given an individual listing. 
During the 1980s two conservation assessments appeared that focused on African primates. The IUCN SSC Primate Specialist Group's Action Plan for African Primate Conservation: 1986-90 (Oates, 1986) made an assessment of the status of every African primate species. The action plan used the five-species classification of red colobus referred to above (see Table 15.1): $P$. badius and $P$. rufomitratus were rated as Vulnerable, $P$. pennantii as Endangered, and P. kirkii and $P$. gordonorum as Highly Endangered. The same species-level classification was followed by Lee and others (1988) in the Threatened Primates of Africa: The IUCN Red Data Book. Lee and others included both species and subspecies; each of the five species was listed as either Vulnerable (P. badius and P. rufomitratus) or Endangered (the remaining three species), and nine subspecies were also given attention through being regarded as of conservation concern. IUCN's 1988 Red List also employed this five species arrangement (IUCN, 1988).

A significant change in the classification of red colobus monkeys for conservation purposes occurred with IUCN's 1996 Red List (IUCN, 1996). Here, all red colobus were lumped into one species, Procolobus badius, with 14 subspecies. The 1996 primate assessments were made by the Primate Specialist Group; Oates and others (1994) is almost certainly the source of the classification employed. Although several subspecies were listed as Endangered or Critically Endangered in the 1996 Red List, the species as a whole was rated as only Near Threatened, based on the new system of threat categories and criteria adopted by IUCN in 1994. The same one-species classification was employed in the revised edition of the Primate Specialist Group's African primate action plan, which appeared in the same year (Oates, 1996).

The IUCN Red List is now published in digital form (www.iucnredlist.org). At the time of writing, the Red List assesses the status of 13 different geographically and taxonomically distinct forms of red colobus, including six species and 10 subspecies (IUCN, 2012). The six species are: Procolobus badius, P. gordonorum, $P$. kirkii, P. pennantii, P. preussi and P. rufomitratus. This arrangement is based in part on IUCN's Global Mammal Assessment of 2008, for which primates were initially assessed at a workshop in 2005; that workshop used Grubb and others (2003) as a primary reference for classification. Grubb and others treat preussi as a subspecies of $P$. pennantii, but the latest Red List elevates this taxon to species level, following Butynski and Kingdon (2013). Of the 13 taxa on the Red List, four are rated as Critically Endangered and seven as Endangered. The taxa foai, lulindicus, ellioti, langi and parmentieri are not individually assessed in the 2012 Red List; they are listed as subspecies of P. rufomitratus which, as a species, is given a rating of Least Concern. The 2012 Red List does not list semlikiensis, following Grubb and others (2003) in treating this taxon as synonymous with ellioti. 
How might changes in classification have affected the attention given by conservationists to the rarest and most threatened of red colobus monkey populations? We will highlight the cases of three forms of red colobus, one probably extinct, one possibly extinct, and one verging on extinction.

Miss Waldron's red colobus of eastern Côte d'Ivoire and western Ghana was referred to as the subspecies Procolobus badius waldroni by Oates (1986), Lee and others (1988) and IUCN (1988). Groves (1989) did not specifically mention waldroni, but also implied that it should be considered as a subspecies of Procolobus badius. The 1996 IUCN Red List gave separate treatments to species and subspecies; all red colobus were treated as one species (Procolobus badius, listed as Near Threatened), while the subspecies P. badius waldroni was listed as Critically Endangered (IUCN, 1996). A few years later, Oates and others (2000) reported that P. b. waldroni was probably extinct, and suggested that even if a few individuals survived, no viable population remained. Subsequently, no reliable record has emerged of any Miss Waldron's red colobus having been seen in the wild, although the remains of a few individuals were found with hunters in Côte d'Ivoire, most recently in 2006 (Oates, 2011). Since 2006, Groves (2007) has elevated this monkey to species status (as Piliocolobus waldronae), and the genetic study by Ting (2008) has also indicated that this might be a reasonable course, confirming the suggestion of Dandelot (1971). We are left to wonder whether recognition of waldroni as a species during the 1980s and 1990s might have directed more conservation attention to this monkey, and averted its extinction. In other words, did taxonomy 'kill' this monkey in the sense used by Morrison and others (2009)?

Bouvier's red colobus is known only from a handful of specimens collected in the nineteenth and early twentieth centuries in the former French Congo (today's Republic of the Congo, or Congo-Brazzaville). Dandelot (1971) classified this monkey as Colobus pennantii bouvieri, based on the similarity of its colour pattern and arrangement of hair on the front of the head to Pennant's red colobus of Bioko. Most subsequent classifications have kept Bouvier's colobus as a subspecies of Pennant's colobus (where that taxon is regarded as a species), or recognised it as one among many subspecies of red colobus in single-species classifications. Exceptions are Ting (2008), who could not confidently place this form into a species because a lack of biomaterials precluded its inclusion in DNA analysis, and Groves (2007), who elevates this form to species rank as Piliocolobus bouvieri, and says that the 'status of this extremely poorly known monkey needs urgent investigation'. The lack of specimens for both morphological and genetic comparative study (and the fact that there have been no substantial scientific observations in the wild) has led this monkey to be seriously neglected. Even the exact locations from where the museum specimens originated are in some doubt, but they seem to lie mostly in the swamp forests on the right bank of the lower Sangha River and near the mouth of the Likouala- 
Mossaka River. A report of red monkeys with light faces and white underparts from the Lefini Reserve in the 1970s (quoted in Groves, 2007) doubtfully refers to this colobus. In the 1996 Red List, bouvieri was rated as an Endangered subspecies of Procolobus badius (IUCN, 1996) and the current Red List includes it as a Critically Endangered subspecies of Procolobus pennantii. Given the lack of any convincing observational reports of this colobus for many decades, there must be a strong possibility that it is extinct; R. Dowsett (pers. comm. to JFO, 1974) noted that monkeys in general are very heavily hunted in this part of Congo, although he added that the area from which bouvieri is known is difficult to access. As with Miss Waldron's colobus we speculate that a clearer taxonomic definition of Bouvier's colobus might have led to it receiving more attention. ${ }^{1}$

The Tana River red colobus of Kenya was listed in the original IUCN Red Data Book as a subspecies, rufomitratus, of the species Colobus badius and rated as Endangered (Simon, 1966). In 1972 the surviving population was estimated at around 1900 individuals (Goodwin et al., 1978). Oates (1986), Lee and others (1988) and IUCN (1988) continued to list the Tana colobus as Endangered, but classified it as a subspecies of Procolobus rufomitratus, a species considered to occupy the Congo Basin and the Western Rift Valley as well as the Tana River, on the basis of the vocal patterns reported by Struhsaker (1981). Kingdon (1997), however, regarded the Tana population as a distinct species, Piliocolobus rufomitratus, a course later followed by Groves $(2001,2007)$ and (using the name Procolobus rufomitratus) by Grubb and others (2003). In 1999-2001, Meikle and Mbora (2004) recorded a total of 613 individuals in the forests along the Tana River, $50 \%$ of the number estimated present in 1994, and referred to the Tana red colobus as 'the most endangered primate species in Africa.' Mbora and Butynski (2009) describe the long-time survival prospects of the Tana colobus as very bleak, especially since the High Court of Kenya ruled in 2007 that the Tana River National Primate Reserve was not properly established by law. However, the current Red List (IUCN, 2012) treats the Tana colobus as the subspecies Procolobus rufomitratus rufomitratus, with the status of Endangered, apparently using an older population estimate of 1,100-1,300 individuals and an assessment that there has not been a significant population decline since 1975.

In addition to the three forms of red colobus we have highlighted, a majority of the remaining 13-15 forms must be regarded as threatened, based on having small, fragmented, and/or rapidly declining populations. Of particular concern are Pennant's red colobus of Bioko Island, the Niger Delta red colobus, and Preuss' red colobus of western Cameroon and eastern Nigeria. Each of these monkeys is rated as Critically Endangered on the current Red List (IUCN, 2012) where they are called Procolobus pennantii pennantii, P. pennantii epieni and

1 Note added in proof: Lieven Devreese (pers. comm.) planned to conduct a field survey to locate any surviving populations of Bouvier's red colobus in the early part of 2015. At the time of writing, no information from this survey was available. 
$P$. preussi respectively - the same classification employed by Grubb and others (2013). Groves (2007) calls these taxa Piliocolobus pennantii, P. epieni and P. preussi.

At least six forms of red colobus monkey could readily be regarded, therefore, as among the most endangered primates in Africa, along with the roloway monkey of Ghana and Côte d'Ivoire, the kipunji of Tanzania, and the mountain and Cross River gorillas. Some combination of these primates has featured for some years, with others, on the list of the World's 25 Most Endangered Primates compiled by the IUCN Primate Specialist Group, Conservation International and the International Primatological Society (see, e.g. Mittermeier et al., 2009). No more than two forms of red colobus (listed as species or subspecies) have ever appeared on this list, however, because of a perceived need (in terms of raising support for primate conservation) to distribute the 25 primates selected as the 'Most Endangered' relatively evenly across Africa, Asia, Madagascar and the Neotropics, as well as across higher taxonomic groups (including strepsirrhines and great apes). This less than objective approach has served to diminish a general awareness of how many red colobus forms are in trouble, and the fact that red colobus often appear on this list as subspecies (in contrast to a large majority of full species occupying the other slots) may also diminish a sense of the crisis faced by these primates.

Differences among red colobus monkey classifications could also potentially affect the prioritisation of areas for conservation. Area-based conservation planning typically compares geographic regions based on their levels of species endemism and/or richness. In general, regions with greater numbers of species, and particularly endemic species, are judged to warrant higher conservation priority and therefore may have a greater chance of being designated for protection efforts. However, levels of species endemism and richness can change depending on what species classification is used, so that a simple change in species concept can alter priority areas for conservation (Agapow et al., 2004). Figures 15.2-15.4 display the distribution of red colobus monkey species according to four different classification schemes. Under a single-species classification (e.g. Oates et al., 1994), there is no area of red colobus species endemism. Using Groves' 2001 nine-species classification (Figure 15.2) East and Central Africa become priority areas for conservation, with six endemic species. Figure 15.3 displays Groves' full application of the PSC to these primates (Groves, 2007) and would give conservation priority to the Congo Basin, which contains nearly half of the red colobus forms. Alternatively, Ting's 2008 classification recognises five species, three of which are endemic to west Central Africa (Figure 15.4). These four different classifications emphasise how differences in taxonomy can create tangible differences in the selection of conservation priority areas. For example, although Myers and others (2000) did not consider the Congo Basin as 
a biodiversity hotspot, Olson and Dinerstein (2002) do consider the Northeastern Congo Basin Moist Forests as a special ecoregion with many endemic species, including 'Piliocolobus oustaleti'.

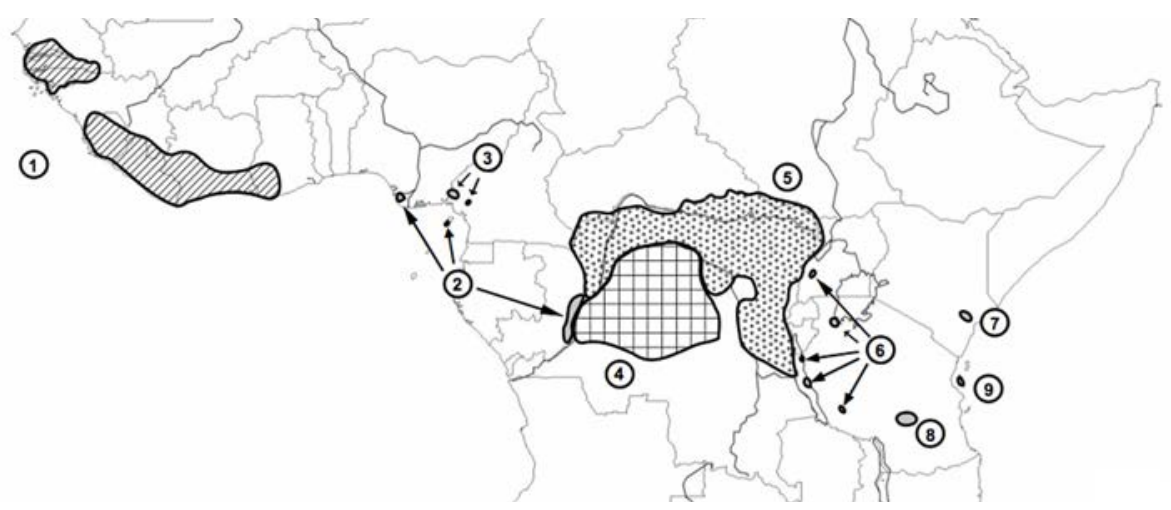

Figure 15.2: Geographical distribution of red colobus according to nine-species arrangement of Groves (2001); $1=P$. badius, $2=P$. pennantii, $3=P$. preussi, $4=P$. tholloni, $5=P$. foai, $6=P$. tephrosceles, $7=P$. rufomitratus, $8=$ P. kirkii, 9 = P. gordonorum.

Source: After Groves (2001); Ting (2008).

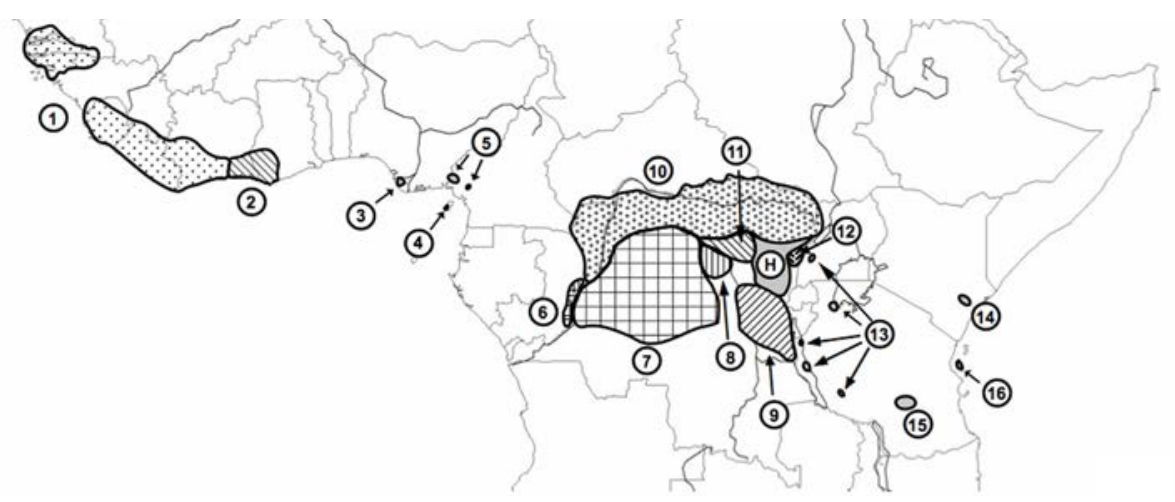

Figure 15.3: Geographical distribution of red colobus according to 16-species arrangement of Groves (2007); $1=P$. badius, $2=P$. waldroni, $3=P$. epieni, $4=$ $P$. pennantii, $5=P$. preussi, $6=P$. bouvieri, $7=P$. tholloni, $8=P$. parmentieri, $9=P$. foai, $10=P$. oustaleti, $11=P$. langi, $12=P$. semlikiensis, $13=$ P. tephrosceles, $14=P$. rufomitratus, $15=P$. gordonorum, $16=P$. kirkii. 


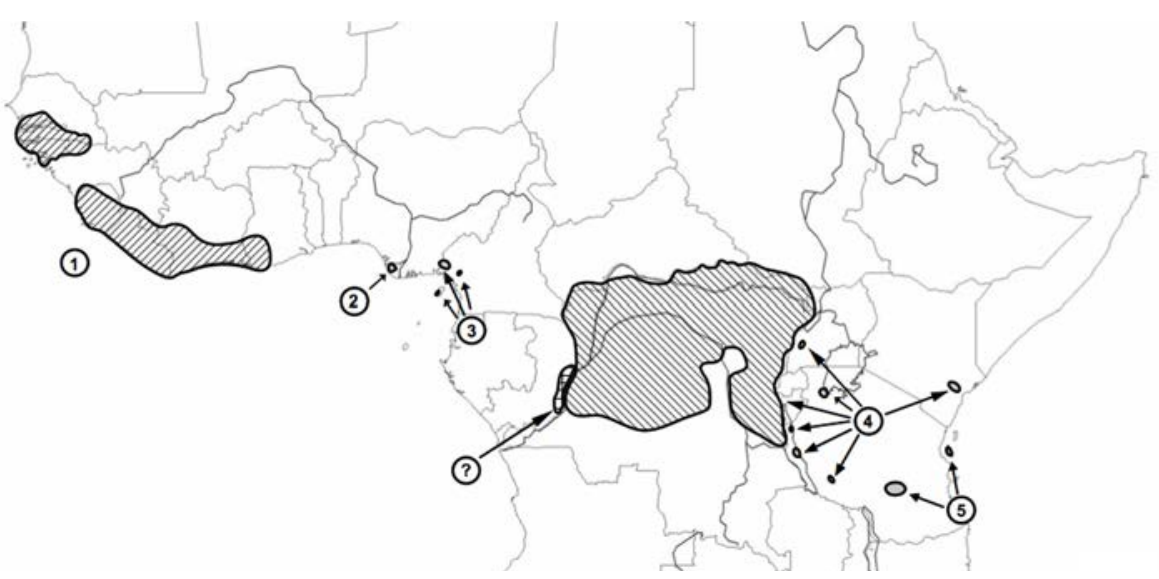

Figure 15.4: Geographical distribution of red colobus according to five-species arrangement of Ting (2008): $1=P$. badius, $2=P$. epieni, $3=P$. pennantii, 4 $=P$. rufomitratus, $5=P$. kirkii; ' ?' is bouvieri which could not be considered in Ting's analysis due to lack of material.

Source: After Ting (2008).

\section{Discussion and conclusions}

The points reviewed in this chapter raise broader issues regarding systematics and conservation biology. It has long been argued that the two fields require better integration if conservation priorities are to be set in the most effective way (e.g. see Rojas, 1992; Dubois, 2003; Mace, 2004; Agapow et al., 2004). Despite progress in this area over the past 20 years, however, large areas of debate remain. One of these is the extent to which conservation concerns should be taken into account when diagnosing taxa. After all, more money and higher levels of protection are commonly directed to endangered populations recognised as distinct species or subspecies. Understanding this, Groves (2001) recognised the Cross River gorilla as the subspecies Gorilla gorilla diehli based more on an appreciation of conservation concern, and as a stimulus to further research, 'than anything else'. However, although a concern for the survival of a population suspected to be more distinctive than is generally recognised can be a useful spur to new taxonomic investigation (which in turn may produce new conservation attention), our view is that elevating populations to higher taxonomic ranks solely due to conservation concern is not valid and can undermine the credibility of instruments such as the Red List in the larger world. 
As we have discussed, different species concepts in the field of systematics lead to different ways of classifying organisms, and most systematists (or at least those who are not strongly wedded to a single concept) would agree that the choice of concept is subjective. In an ideal world, we would all agree on a single species concept that can be applied consistently across all taxa. However, such agreement is very unlikely, and we are thus stuck with a plurality of species concepts. Given this circumstance, we believe it would be sensible to choose species concepts based on their applicability to the particular study organisms, as long as researchers are transparent about which species concept they are using. This would help ensure that taxonomic revisions are due to new data and discoveries rather than to a simple change in species concept, and it would prevent populations being forced into species concepts that are poorly applicable.

Choosing species concepts based on circumstance would also have an effect on conservation planning by generating stable classifications more quickly. For example, the BSC has been argued to be most appropriate for conservation planning purposes because it is process-based, grounded in population genetics, and looks to the present and future (Frankham et al., 2012). While we believe this to be true in theory, conservation decisions have to be made by balancing what is best in theory with what can be implemented in practice. For example, application of the BSC to allopatric populations can be very time and labour intensive and produces subjective classifications. Use of the BSC can therefore be a hindrance to urgent action in these circumstances, especially if multiple types of data are required and the organisms concerned are rare and/or live in remote areas. The red colobus monkeys are an example of this problem. While scientists have spent several decades attempting to delimit BSC boundaries in these monkeys, one form has probably gone extinct (Miss Waldron's red colobus), one may be extinct (Bouvier's red colobus), and several more have declined to precarious states.

Use of the PSC for allopatric populations has advantages because it produces objective and unambiguous classifications (Vogler and DeSalle, 1994; Gippoliti and Groves, 2013). Some have suggested that phylogenetic species are not necessarily evolutionarily meaningful and that the PSC undermines the importance of species in the evolutionary process (e.g. Tattersall, 2007, 2013). While we appreciate these concerns, it is important to point out that the most significant unit of evolution is the population, and the PSC recognises species as populations that have diverged in some manner. Even if this divergence is not enough to produce reproductive isolation, the evolutionary significance of whether or not two populations can potentially interbreed is moot if they are allopatric and will never come into contact. There is thus more recognition of evolutionary theory in the Phylogenetic Species Concept than some acknowledge. 
The use of phylogenetic species does not preclude further research into, and incorporation of, more process-based and adaptive frameworks in conservation, such as grouping certain species together into larger management units or identifying divergent taxa as high conservation priorities (Gippoliti and Groves, 2013).

We consider that the instability in the taxonomic treatment of red colobus has been one factor that has led these monkeys to be relatively neglected in conservation planning compared to some other primates, and that this neglect may have led to a lack of sufficient action to halt the decline and possible extinction of some distinctive populations. Unstable classifications may have caused confusion, and led to less focused conservation action than has been needed. The primary cause of the taxonomic instability has been the inability of scientists to diagnose species in this group according to the Biological Species Concept and the resulting gradual transition to the application of the Phylogenetic Species Concept. Red colobus monkey conservation might have benefitted if the PSC had been applied at a much earlier point. We do not believe that application of the PSC undermines the scientific credibility of either systematics or conservation as long as those using it are transparent regarding its use. While the case of the red colobus is only a single example of an advantage of applying the PSC over the BSC, it is possible that application of the PSC across other taxonomic groups could prevent similar dire situations from arising in other organisms.

We suggest that the application of taxonomy to conservation planning could also be improved if conservation authorities such as the IUCN SSC Primate Specialist Group used standardised species lists updated at regular intervals (e.g. five years); such lists should be accompanied by a clear statement on the species concept used to produce the list. The IUCN Red List would then follow the standardised lists formulated by specialist groups. Meanwhile, normal research in systematics would continue, and its findings be considered during reviews of standard lists.

However, although taxonomic instability may have contributed to the lack of conservation attention given to red colobus monkeys, despite the precarious status of many forms, it is almost certainly not the only factor leading to their neglect. Even though their classification has been highly unstable, red colobus have long featured in some way on the IUCN Red List. We conclude that taxonomy is probably only one factor in their neglect compared to, for instance, great apes and lemurs. Morrison and others (2009) have found that the 'charisma' of animals like red wolves, polar bears and green turtles has meant that there has been no reduction in the conservation efforts devoted to them despite taxonomic research findings that question their species status. Red colobus lack the charisma that great apes gain from their close similarity 
to humans, their intelligence and their size. They lack the 'cuteness' of furry lemurs. Both great apes and lemurs are readily seen close-up in many zoos, and have been the focus of a great deal of media attention. Red colobus, which have never survived very long in captivity, lack all these attributes.

While a case could be made for conservation action to be undertaken largely independently of current taxonomic opinion, as happens today with some particularly charismatic animals, if this course was generally followed then objective conservation planning would be almost impossible. Those organisms less charismatic to the general public would have a low priority for conservation attention. Thus good taxonomy is essential for effective conservation. By dedicating a lifetime to describing biological diversity, Colin Groves has greatly aided conservation efforts in a wide range of taxa. His relatively recent endorsement of the PSC has helped illuminate the issue of the role of taxonomy in conservation and produced a healthy debate.

\section{Acknowledgements}

We thank Tom Struhsaker for first introducing us to red colobus, and for his huge contribution to an understanding of these monkeys' biology. We are also grateful to Eric Delson and Cliff Jolly for stimulating discussions about systematics and taxonomic theory, and to Colin Groves and the late Peter Grubb for many thought-provoking conversations about primate and especially red colobus taxonomy. As we made final edits to this chapter we learned of the death (on 5 July 2014) of Dr Peter Marler. Marler briefly studied red colobus in Uganda's Kibale Forest in 1965 and encouraged Tom Struhsaker - who had been his PhD student - to undertake a more comprehensive study of these monkeys. JFO joined Tom in Kibale in 1970, leading to an affiliation with the Marler lab at Rockefeller University which lasted into the 1980s and was a life-changing experience. Our contribution is therefore dedicated to the memory of Peter Marler.

\section{References}

Agapow PM, Bininda-Emonds ORP, Crandall KA, Gittleman JL, Mace GM, Marshall JC, Purvis A. 2004. The impact of species concept on biodiversity studies. Q Rev Biol 79:161-179.

Bock WJ. 2004. Species: The concept, category and taxon. J Zool Syst Evol Res 42:178-190. 
Butynski TM, Kingdon J. 2013. Procolobus preussi Preuss' red colobus. In: Butynski TM, Kingdon J, Kalina, J, editors. Mammals of Africa. Vol. II: Primates. London: Bloomsbury Press. pp. 134-136.

Cardini A, Elton S. 2009. Geographical and taxonomic influences on cranial variation in red colobus monkeys (Primates, Colobinae): Introducing a new approach to 'morph' monkeys. Global Ecol Biogeogr 18:249-263.

Coyne JA, Orr HA. 2004. Speciation. Sunderland, MA: Sinauer Associates.

Cracraft JL. 1983. Species concepts and speciation analysis. Curr Ornithol $1: 159-187$.

Dandelot P. 1971. Order Primates. Part 3, The mammals of Africa: An identification manual. Washington, DC: Smithsonian Institution Press.

Davis JI, Nixon KC. 1992. Populations, genetic-variation, and the delimitation of phylogenetic species. Syst Biol 41:421-435.

Dubois A. 2003. The relationships between taxonomy and conservation biology in the century of extinctions. C R Biol 326:S9-S21.

Frankham R, Ballou JD, Dudash MR, Eldridge MDB, Fenster CB, Lacy RC, Mendelson JR III, Porton IJ, Ralls K, Ryder OA. 2012. Implications of different species concepts for conserving biodiversity. Biol Conserv 153:25-31.

Gippoliti S, Groves CP. 2013. 'Taxonomic inflation' in the historical context of mammalogy and conservation. Hystrix 23:1-7.

Goldstein PZ, DeSalle R. 2000. Phylogenetic species, nested hierarchies, and character fixation. Cladistics 16:364-384.

Goodman M. 1996. Epilogue: A personal account of the origins of a new paradigm. Mol Phylogenet Evol 51:269-285.

Goodwin HA, Holloway CW, Thornback J. 1978. Red data book. Vol. 1: Mammalia. Revised edition. Morges, Switzerland: IUCN.

Groves CP. 1966. Variation in the skulls of gorillas with particular reference to ecology. PhD thesis, University College London.

Groves CP. 1967. Ecology and taxonomy of the gorilla. Nature 213:890-893.

Groves CP. 1970a. Population systematics of the gorilla. J Zool, Lond 161:287300. 
Taxonomic Tapestries

Groves CP. 1970b. The forgotten leaf-eaters, and the phylogeny of the Colobinae. In: Napier JR, Napier PH, editors. Old World monkeys: Evolution, systematics, and behavior. New York: Academic Press. pp. 555-587.

Groves CP. 1989. A theory of human and primate evolution. Oxford: Oxford University Press.

Groves CP. 2001. Primate taxonomy. Washington, DC: Smithsonian Institution Press.

Groves CP. 2004. The what, why, and how of primate taxonomy. Int J Primatol 25:1105-1126.

Groves CP. 2007. The taxonomic diversity of the Colobinae in Africa. J Anthropol Sci 85:7-34.

Groves CP. 2012. Species concepts in primates. Am J Primatol 74:687-691.

Grubb PJ, Butynski TM, Oates JF, Bearder SK, Disotell TR, Groves CP, Struhsaker TT. 2003. Assessment of the diversity of African primates. Int J Primatol 24:1301-1357.

Grubb PJ, Glander K, Siex K. 2010. Annotated list and measurements of red colobus taxa. Appendix 1.1. In: Struhsaker TT, editor. The red colobus monkeys. Oxford: Oxford University Press. pp. 277-284.

Grubb PJ, Struhsaker TT, Siex KS. 2013. Subgenus Piliocolobus. In: Butynski TM, Kingdon J, Kalina J, editors. Mammals of Africa. Volume II: Primates. London: Bloomsbury Press. pp. 125-128.

Hennig W. 1966. Phylogenetic systematics. Champaign, IL: University of Illinois Press.

Huxley J. 1942. Evolution. The modern synthesis. London: Allen and Unwin.

International Union for Conservation of Nature (IUCN). 1988. 1988 IUCN Red List of threatened animals. Gland, Switzerland: IUCN.

IUCN. 1996. 1996 IUCN Red List of threatened animals. Gland, Switzerland: IUCN.

IUCN. 2012. IUCN Red List of threatened species. Version 2012.2. www. iucnredlist.org. accessed 7 May 2013.

Kingdon J. 1997. The Kingdon field guide to African mammals. San Diego: Academic Press. 
Kuhn H-J. 1967. Zur Systematik der Cercopithecidae. In: Starck D, Schneider R, Kuhn H-J, editors. Neue Ergebnisse der Primatologie. Stuttgart: Gustav Ficher. pp. 25-46.

Lee PC, Thornback J, Bennett EL. 1988. Threatened primates of Africa: The IUCN Red Data book. Gland, Switzerland: IUCN.

Mace GM. 2004. The role of taxonomy in species conservation. Phil Trans $R$ Soc Lond B:Biol Sci 359:711-719.

Marler P. 1970. Vocalizations of East African monkeys. Folia Primatol 13:81-91.

Mayr E. 1942. Systematics and the origin of species. New York: Columbia University Press.

Mayr E. 1996. What is a species, and what is not? Philos Sci 63:262-277.

Mbora DNM, Butynski T. 2009. Tana River red colobus. In: Mittermeier RA et al. Primates in peril: The world's 25 most endangered primates 2008-2010. Primate Conserv 24:15.

Mbora DNM, Meikle DB. 2004. Forest fragmentation and the distribution, abundance and conservation of the Tana River red colobus (Procolobus rufomitratus). Biol Conserv 118:67-77.

Mittermeier RA, Wallis J, Rylands AB, Ganzhorn JU, Oates JF, Williamson EA, Palacios E, Heymann EW, Kierulff MCM, Yongcheng L, Supriatna J, Roos C, Walker S, Cortés-Ortiz L, Schwitzer C. 2009. Primates in peril: The world's 25 most endangered primates 2008-2010. Primate Conserv 24:1-57.

Morrison WR III, Lohr JL, Duchen P, Wilches R, Trujillo D, Mair M, Renner SS. 2009. The impact of taxonomic change on conservation: Does it kill, can it save, or is it just irrelevant? Biol Conserv 142:3201-3206.

Myers N, Mittermeier RA, Mittermeier CG, da Fonseca GAB, Kent J. 2000. Biodiversity hotspots for conservation priorities. Nature 403:853-858.

Napier JR, Napier PH. 1967. A handbook of living primates: Morphology, ecology and behaviour of nonhuman primates. London: Academic Press.

Napier PH. 1985. Catalogue of primates in the British Museum (Natural History) and elsewhere in the British Isles. Part III: Family Cercopithecidae, Subfamily Colobinae. London: British Museum (Natural History).

Oates JF. 1986. Action plan for African primate conservation: 1986-90. Stony Brook, NY: IUCN/SSC Primate Specialist Group. 
Taxonomic Tapestries

Oates JF. 1996. African primates: Status survey and conservation action plan. Revised edition. Gland, Switzerland: IUCN.

Oates JF, Abedi-Lartey M, McGraw WS, Struhsaker TT, Whitesides GH. 2000. Extinction of a West African red colobus monkey. Conserv Biol 14:15261532 .

Oates JF, Davies AG, Delson E. 1994. The diversity of living colobines. In: Davies AG, Oates JF, editors. Colobine monkeys: Their ecology, behaviour and evolution. Cambridge: Cambridge University Press. pp. 45-73.

Olson DM, Dinerstein E. 2002. The Global 200: Priority ecoregions for global conservation. Ann Missouri Bot Gard 89:199-224.

Rahm UH. 1970. Ecology, zoogeography, and systematics of some African forest monkeys. In: Napier JR, Napier PH, editors. Old World monkeys: Evolution, systematics, and behavior. NewYork: Academic Press. pp. 589-626.

Rojas, M. 1992. The species problem and conservation: What are we protecting? Conserv Biol 6:170-178.

Simon N. 1966. Red data book. Volume 1: Mammalia, a compilation. Morges, Switzerland: IUCN.

Sokal RR, Crovello TJ. 1970. The biological species concept: A critical evaluation. Am Nat 104:127-153.

Struhsaker TT. 1975. The red colobus monkey. Chicago: University of Chicago Press.

Struhsaker TT. 1981. Vocalizations, phylogeny, and palaeogeography of red colobus monkeys (Colobus badius). Afr J Ecol 19:265-283.

Struhsaker TT. 2010. The red colobus monkeys. Oxford: Oxford University Press.

Szalay FS. 1993. Species concepts: The tested, the untestable, and the redundant. In: Kimbel WH, Martin LB, editors. Species, species concepts, and primate evolution. New York: Plenum Press. pp. 21-41.

Tattersall I. 2007. Madagascar's lemurs: Cryptic diversity or taxonomic inflation? Evol Anthropol 16:12-23.

Tattersall I. 2013. Species-level diversity among Malagasy lemurs. In: Masters J, Gamba M, Génin F, editors. Leaping ahead: Advances in prosimian biology. New York: Springer. pp. 11-20. 
Thorington RW Jr, Groves CP. 1970. An annotated classification of the Cercopithecoidea. In: Napier JR, Napier PH, editors. Old World monkeys: Evolution, systematics, and behavior. New York: Academic Press. pp. 629647.

Ting N. 2008. Molecular systematics of red colobus monkeys (Procolobus [Piliocolobus]): Understanding the evolution of an endangered primate. $\mathrm{PhD}$ Thesis, City University of New York.

Verheyen WN. 1962. Contribution à la craniologie comparée des Primates: Les genres Colobus Illiger 1811 et Cercopithecus Linné 1758. Ann Musée Roy Afr Centr Ser 8 Sci Zool 105:1-255.

Vogler AP, Desalle R. 1994. Diagnosing units of conservation management. Conserv Biol 8:354-363.

Wolfheim JH. 1983. Primates of the world: Distribution, abundance, and conservation. Seattle: University of Washington Press. 
This text is taken from Taxonomic Tapestries: The Threads of Evolutionary, Behavioural and Conservation Research, edited by Alison M Behie and Marc F Oxenham, published 2015 by ANU Press, The Australian National University, Canberra, Australia. 